\title{
Common Problems and Countermeasures in the Construction Drawing Design
}

\author{
Yongqian Liu \\ Liaoning Jianzhu Vocational College, China,312000
}

Keywords: construction engineering; construction drawing design; common problems; countermeasures

\begin{abstract}
With the rapid development of China's socialist market economy, there are more and more construction projects in various places. In order to ensure the quality of the building, the designer should carefully and comprehensively design the construction drawings in strict accordance with the relevant regulations and systems, so as to ensure the quality of the construction drawing design, thus facilitating on-site construction. At present, there are still some problems in construction drawing design of construction engineering in China, which seriously affects the construction quality of construction engineering. This paper summarizes the common problems existing in the construction drawing design, and then puts forward the strategies and measures to solve the problems in the construction drawing design, which can be used for reference in optimizing the construction drawing design of civil buildings.
\end{abstract}

\section{Introduction}

The rapid development of China's social economy has promoted the prosperity of the real estate market, and the development of the construction industry has enabled many new design units to emerge. Although the construction industry has improved the overall quality and comprehensive performance of construction projects, the design unit and design of the construction drawings. The personnel put forward more new requirements, but due to various internal and external factors in the construction drawing design, there are still some common problems in the construction drawing design. The problem of building construction drawing design will not only seriously affect the cost of the construction unit and the investment of the owner, but may even lead to rework and rework of the construction project. Therefore, the design unit must thoroughly solve these common problems through some measures to ensure that the quality of the building construction drawing design can meet the actual needs of the project ${ }^{[1]}$.

\section{Basic composition of building construction drawing design}

On the whole, the basic composition of building construction drawing design can be divided into text and graphic parts. Among them, the text part mainly includes the cover list, design description, construction material table, energy-saving calculation book and sunshine calculation book. The graphic part mainly includes the general plan of the building, the plan, the elevation, the section and 
the detailed drawings.

When designing the building construction drawings, the macro-level qualitative construction plan should be designed according to the plan first. Secondly, the preliminary design should be carried out to deepen the design of the plan and increase the professional factors. Finally, the general plan construction drawing and building structure in the construction drawing design process. The construction drawings, water supply and drainage construction drawings, HVAC electrical construction drawings, power construction drawings, construction drawing estimates and budgets are specifically quantified, as shown in Figure 1.

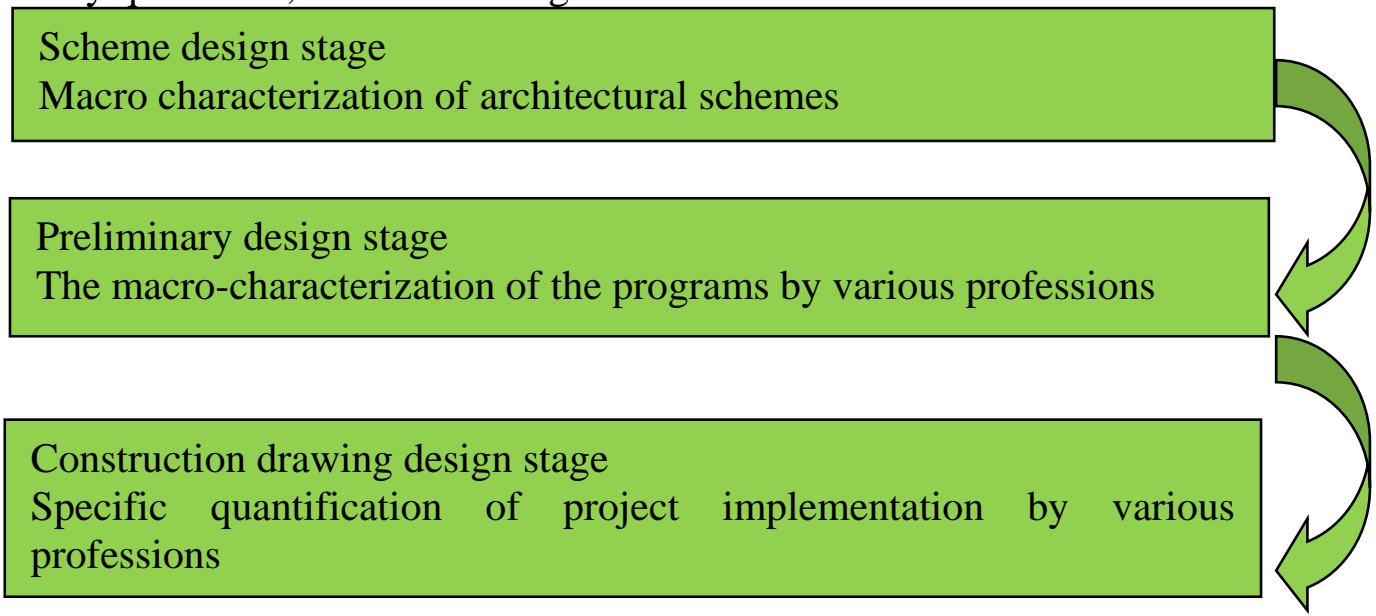

Figure 1 Architectural design

\section{Common problems in building construction drawing design}

\subsection{General plan missing item}

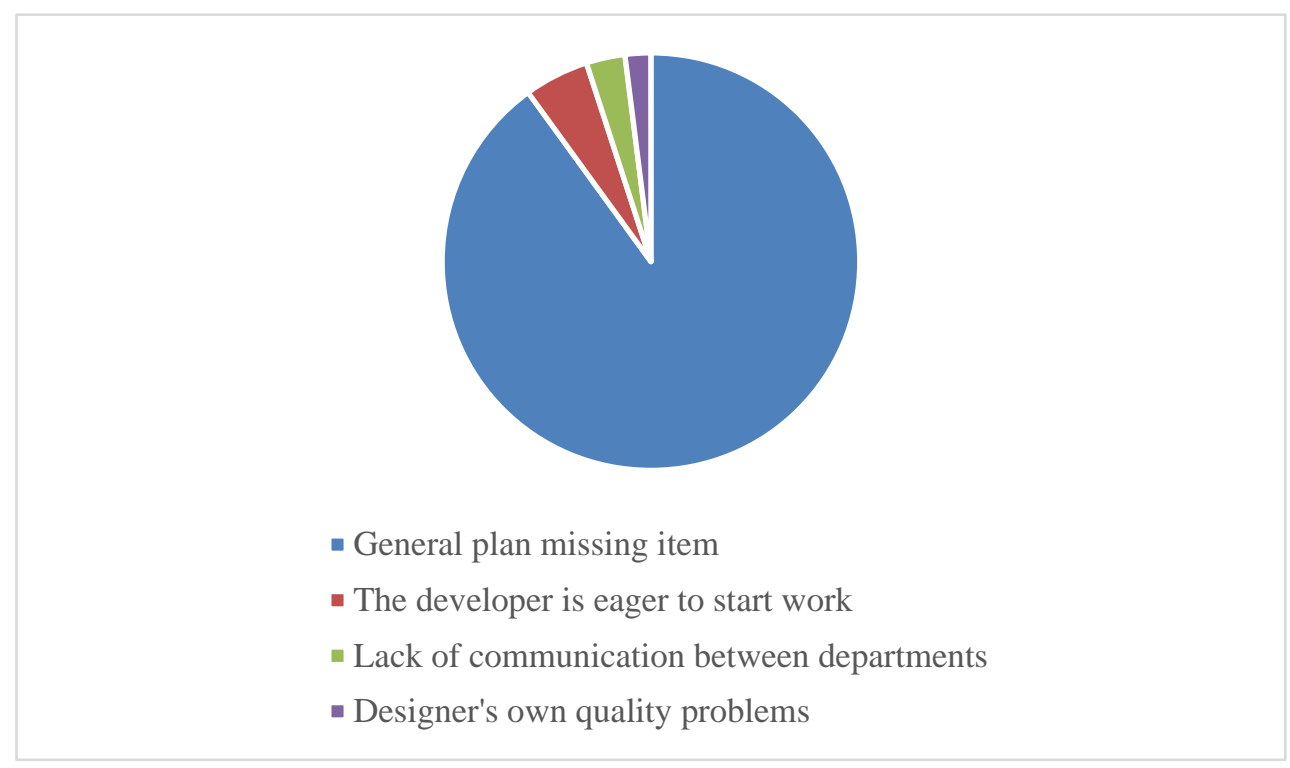

Figure 2 The proportion of common problems in building construction drawing design

At the current stage of construction drawing review, the total plan missing problem accounted for more than $90 \%$ of the total number of problems, especially in small and medium-sized design units with poor qualifications and poor business capabilities. Figure 2 shows the proportion of common problems in the construction drawing design. According to the "Provisions on the Depth of 
Construction Engineering Design Documents" promulgated by the Ministry of Construction of China, the design depth of the master plan must meet the requirements of relevant design specifications. For example, in most of the current civil construction drawing design, there is a serious lack of design of building spacing, plaza, road layout, etc. In the road design, there is also a serious lack of design content in terms of turning radius, width, slope and plane intersection. The overall design quality of the civil construction drawing cannot meet the requirements of the residents ${ }^{[2]}$.

\subsection{The developer is eager to start work}

Many buildings in China are built by developers. The developers cooperate by selecting suitable design units. Under the premise of maximizing profits, the design units are required to design low-cost drawings and ensure the construction quality of the project. In order to improve the progress, it is often required to speed up the construction period, which makes many engineering designers unable to give full play to their own ideas, ignoring some details in the construction design, which leads to many problems.

\subsection{Lack of adequate communication and collaboration across departments}

Usually, when designing an building, it is necessary to have close contact between departments and a clear division of labor. However, at this stage, many relevant departments have not achieved sufficient cooperation and communication, which leads to the inconsistency of an architectural drawing. In particular, some detailed problems are most likely to cause disputes. In addition, there are It may cause the drawings to be inconsistent with the actual construction conditions, thus increasing the construction cost and difficulty ${ }^{[3]}$.

\subsection{Designer's own quality problems}

At this stage, the designers in the field of construction engineering in China pay too much attention to the speed of drawing, seriously neglecting the targeted design of the building construction drawings. Moreover, the relevant professional knowledge of the designers is not updated in time, and the relevant standards and specifications are not thoroughly understood. Learning to master new technologies, new knowledge and new theories in design, the depth of current building construction drawing design can not meet the development requirements of the construction engineering field, so the designer's own quality problems also greatly limit the construction engineering sustainable development.

\section{Strategies for strengthening the quality of architectural construction drawing design}

\subsection{Purifying the architectural design market environment}

Purify the market environment of architectural design and avoid the bad competition of design units: under the market economy, the social adverse effects brought about by bad competition have become more and more obvious. This is not the fault of reform and opening up and the market economy, but the huge market economy. Under the pressure of competition, some architectural design units have a relatively high risk of survival because of their weak market competitiveness. The importance attached to the foreword benefits far exceeds the importance attached to their own development vision, and thus neglects to some extent. Its own sustainable development, using some unfair competition methods, disrupted the normal architectural design market order. Therefore, our 
government departments should increase the rectification of the architectural design industry, use legal weapons to promptly bring order out of chaos, purify the architectural design market environment, and improve the overall level of the industry ${ }^{[4]}$.

\subsection{Improve the professionalism of designers}

The level of professionalism of the designer greatly affects the level of the entire building design unit. It can be said that the lack of professional ability of the designer will directly lead to design errors in the construction drawing, which will not only affect the subsequent construction work, but also reduce the design quality of the entire civil building. As the chief engineer of building construction design, the professional mission and social responsibility of each designer is very important. It is related to the basic living needs of each resident. Therefore, we must effectively improve the professional level of designers, and constantly improve their design level with more reasonable and more humane design concepts. At the same time, each design unit must continuously organize designers to participate in training activities or conduct on-the-spot investigations to enrich their design experience ${ }^{[5]}$.

\subsection{Establish a sound management system}

In order to achieve the goal of survival and development in the fierce market competition, the design unit must establish a scientific and perfect quality supervision and management system, and improve the quality of the design drawings of the designers by increasing supervision. "Quality First" is the core goal and concept of the work of various departments of the design unit. This will not only help the design unit to effectively improve the overall design quality of the building construction, but also help the design unit and the construction enterprise to further expand the market.

\subsection{Strengthen communication and communication within each design department}

The internal design department of the design unit is mutually independent and unified, so the departments need to be combined with the actual situation of the project. Each design department within the design unit is independent and unified, so it is necessary to combine the actual situation of construction, promote the cooperation between each department, strengthen the communication and cooperation between each department, so as to design a most reasonable design scheme. Also should avoid conflicts between the design department, so as to effectively improve work efficiency between different departments, prompting a design unit in operation and management can effective internal communication and makes some specific construction information can get sufficient flow internally and sharing, so as to achieve the aim of improving work efficiency.

\section{Conclusions}

In general, the construction drawing design to a large extent determines the quality of the construction project, which must be paid enough attention to. Therefore, in the construction drawing design, some common problems need to be solved, so as to ensure the quality of construction drawing design and meet the needs of the actual project. In order to solve the problem of architectural construction drawing design, it is necessary to require relevant design units to strengthen the management of enterprises, improve the comprehensive quality of designers, strengthen the communication and exchange within each design department, and ensure that design units can provide more high-quality construction drawings for China's construction industry. 


\section{References}

[1] Tang Yuting, Han Baijian. Common Problems and Countermeasures in the Construction Drawing Design of Civil Buildings[J]. China Building Materials Science \& Technology, 2015(2): 109-110.

[2] Niu Yumeng. Common Problems and Countermeasures in the Construction Drawing Design of Civil Buildings[J]. Residential and Real Estate, 2017(21):133.

[3] Zhang Kuan, Zhou Yiyuan. Analysis and Countermeasures of Common Problems in Construction Water Supply and Drainage Construction Drawing Design Review [J]. Science and Technology Information, 2016, 14(15): 55-56.

[4] Yang Yahong. Problems and Countermeasures for Fire Protection Design and Completion Acceptance of Building Construction Drawings[J]. Residential and Real Estate, 2016(18):00099-00100.

[5] Huang Mugang. Analysis of Some Problems and Countermeasures in the Construction Drawing Design of Civil Buildings[J]. City Geography, 2016(18). 